\title{
Prevalence and Demographic of Spontaneous Intracerebral Hemorrhage Cases In Haji Adam Malik Hospital From 2018-2019
}

\author{
Muhammad Ari Irsyad ${ }^{1}$,Tommy Rizky Hutagalung', Luthfi Farhan ${ }^{1}$, Muhammad Ihsan Z. Tala ${ }^{1}$ \\ ${ }^{1}$ Department of Neurosurgery, Universitas Sumatera Utara, Medan, Indonesia
}

\begin{abstract}
Introduction: Spontaneous intracerebral hemorrhage (ICH) represents as cerebral parenchymal bleeding that may also extend into ventricular (IVH). ICH, as a stroke subtype, is associated with poor neurological outcome as well as high mortality in $40 \%$ cases. Hypertension is the main and the most common risk factor in the development of $\mathrm{ICH}$, particularly in the basal ganglia, thalamus, pons and deep cerebellar white matter. Hypertensive ICH in these localizations are particularly common in patients with chronic hypertension and they are not in compliance with blood pressure management. Other risk factor such as smoking and diabetes meilitus. Case Report: This retrospective study reviewed patient who were diagnosed with spontaneous intracerebral hemorrhage from January 2018 until December 2019 at the Haji Adam Malik General Hospital Medan,Indonesia. The patient's demographic data and number of cases are collected. There were 163 cases of pure spontaneous ICH and 159 cases of Spontaneous ICH with IVH were among the total cases of ICH from 2018 to 2019.

Discussion: Based on data at the Haji Adam Malik General Hospital Medan from 2018 to 2019,there are differences in the number of men and women proportion in the incident of pure ICH , for men who are 110 people around $67 \%$ while in women it is 53 people or about $32 \%$. The incidence also higher in diabetes meilitus and smoking patient.

Conclusion: We reported 163 cases of pure ICH and 159 cases of ICH with IVH. Based on demographic examination, male are dominant about $67 \%$ of total cases. Based on the biggest risk factors in patients with spontaneous ICH are hypertension, in the case of spontaneous ICH with IVH the biggest risk factor was smoking.
\end{abstract}

Keyword: Spontaneous intracerebral hemorrhage, intraventricular hemorrhage, Stroke hemorrhage

\section{Introduction}

Spontaneous intracerebral hemorrhage (ICH) represents cerebral parenchymal bleeding that may also extend into ventricular. $\mathrm{ICH}$, as a stroke subtype, is associated with poor neurological outcome as well as high mortality (about 40\%). According to the National Vital Statistics Report, stroke is the third leading cause of death in the United States, behind only heart disease and cancer, and is responsible for nearly $6 \%$ of total deaths on an annual basis. ICH accounts for approximately $10 \%$ of all strokes with an annual incidence of between 15.9 and 32.9 per 100,000. A sharp increase in incidence occurs in patients more than 75 years old, and it is even higher in patients older than 85, with reported incidence rates as high as 309.8 per 100,000 , nearly 7 times greater than the rate in the general population. ICH represents around 10-15\% of all strokes in Europe, USA and Australia, while in Asia it

*Corresponding author at: Department of Neurosurgery,Universitas Sumatera Utara,Medan, Indonesia

Copyright (C) 2020 Published by Talenta Publisher, ISSN: 2686-0848 ; DOI : 10.32734

Journal Homepage: http://aanhsj.usu.ac.id 
accounts for about 20-30\%. It has been reported that every year 2 million people worldwide have ICH. In 2010 there were 5.3 million cases of hemorrhagic stroke worldwide. The global incidence of ICH is 24.6 per 100,000 person years, although the incidence varies extremely among different populations, ranging from 7 per 100,000 in Rochester, Minnesota, to 57.6 per 100,000 in China and Japan.[1] [2] [3] [4]

Meta-analysis have shown that the incidence of ICH between 1980 and 2008 had not declined. Though less frequent than ischemic stroke, the overall mortality of ICH is significantly greater, with 30-day mortality estimated at $44 \%$ to $52 \%$ and half of all deaths occurring within the first 2 days of hemorrhage. Arterial hypertension and the use of antithrombotic-anticoagulant agents are the most prominent predisposing factors . Morbidity and mortality are high for $\mathrm{ICH}$, with a 30-day mortality rate of about $40 \%$ commonly reported. [1] [2] [3] [4]

Hypertension is the main and the most common risk factor in the development of $\mathrm{ICH}$, particularly in the basal ganglia, thalamus, pons and deep cerebellar white matter. Hypertensive ICH in these localizations are particularly common in patients with chronic hypertension, and they are not in compliance with blood pressure management. In chronic uncontrolled hypertension the pathophysiologic mechanism is the development of Charcot Bouchard aneurysms within the distal microarteriolar vascular bed in three arterial territories: lenticulostriates, thalamoperforators and paramedian branches of the basilar artery. Most bleeding in ICH related to hypertension occur at or near the bifurcation of small penetrating arteries that originate from basilar arterie or the anterior, middle or posterior cerebral arteries. Multiple sites of rupture can be found in small artery branches of 50-700 $\mathrm{mm}$ in diameter, and some ruptures are associated with layers of platelet and fibrin aggregates. These lesions include breakage of elastic lamina, atrophy and fragmentation of smooth muscle, dissections and granular or vesicular cellular degeneration.[5] [6] [7]

In elderly patients lipid deposition as a result of severe atherosclerosis can be found. In small proportion of patients fibrinoid necrosis of the subendothelium with subsequent focal dilatations (microaneurysms) which can lead to rupture in small proportion of patients is being described.[8] [9] [10]

\section{Case Report}

This study was retrospective study, collecting data of Prevalence and Epidemiology of Spontaneous Intracerebral Hemorrhage In Haji Adam Malik Hospital from January 2018 until December 2019. 
Inclusion criteria:

1. Patients $>18$ years of age

2. Patients with Spontaneous intracerebral hemorrhage

3. Patients with a complete medical record of risk factors

Exclusion Criteria:

1. Spontaneous intracerebral hemorrhage posterior fossa

2. Spontaneous intracerebral hemorrhage brainstem

3. Spontaneous intracerebral hemorrhage accompanied by SAH due to anurysmal rupture

\begin{tabular}{cc}
\hline Diagnose & Number of Cases \\
\hline Spontaneous Intracerebral Hemorrhage (ICH) & 163 \\
Spontaneous ICH + IVH & 159 \\
\hline
\end{tabular}

Table 1. Number of Cases

\begin{tabular}{llcc}
\hline No & Demographic & $\begin{array}{c}\text { Intracerebral } \\
\text { Hemorrhage }\end{array}$ & $\begin{array}{c}\text { Spontaneous ICH } \\
\text { with IVH }\end{array}$ \\
\hline 1 & Male & $110(67 \%)$ & $95(64 \%)$ \\
& Female & $53(32 \%)$ & $64(36 \%)$ \\
2 & Hypertension & $126(77 \%)$ & $116(73 \%)$ \\
& Non Hypertension & $37(22 \%)$ & $43(27 \%)$ \\
3. & Diabetes Meilitus & $113(69 \%)$ & $111(70 \%)$ \\
& Non Diabetes & $50(30 \%)$ & $48(30 \%)$ \\
& Meilitus & & $128(81 \%)$ \\
4. & Smoker & $115(70 \%)$ & $31(19 \%)$ \\
& Non Smoker & $48(29 \%)$ & \\
\hline
\end{tabular}

Table 2. Demographic and Risk Factor

\section{Discussion}

Based on these study, there were 163 cases of pure spontaneous ICH patients and 159 cases of Spontaneous ICH with IVH were among the total cases of ICH from 2018 to 2019. Hanley reported that spontaneous ICH with IVH is about $42 \%-55 \%$ of cases at a tertiary care center in Yogyakarta, Indonesia. IVH is an independent predictor of worse outcomes with mortality rates of $29-78 \%$, compared to $5-29 \%$ for ICH without IVH. This finding was lower 
in our study, whereas ICH with IVH was account for $24 \%$. This is slightly different than the case that we found that stated there are $30 \%$ from the entire case. This might be occured due to the fact that ICH with IVH was an independent factor associated with higher mortality. This data is compared to data on world cases of 24.6 per 100,000 person years, although the incidence varies widely in between different populations, ranging from 7 per 100,000 in Rochester, Minnesota, to 57.6 per 100,000 in China and Japan. Based on the comparison of these data, the ICH cases at the Adam Malik Haji Hospital are still relatively few, this is probably because there are already many neurosurgical health service centers in peripheral hospitals.[2]

In a study conducted at the Sanglah Bali Hospital showed a male predominance pattern, which was also found in the most study of stroke. Overall male to female ratio in this study was 1,6:1. Based on these data, there is a similarity of data, based on data at the General Hospital of Hajj Adam Malik Medan from 2018 to 2019 there are differences in the number of men and women in the pure incident of $\mathrm{ICH}$, for men who are 110 people around $67 \%$ while in women it is 53 people or about $32 \%$, Sex differences were also documented in many previous studies. The reasons are still unclear. However, some possible hypotheses were raised, one of those was the positive effect of estrogen on the cerebral circulation. It is shown that lifetime exposure of ovarian estrogen may protect against ischemic stroke. Male predominance also found on many ischemic heart disease studies. Thus, the key of observed sex difference might relate to cardiovascular components such as overall higher blood pressure in men compared to women of similar age. This is in accordance with the fact that most of the cardiovascular disease involving larger vessels, including ischemic heart disease and peripheral artery disease were more common in men. The similarities between these two disease entities may result from many other shared risk factors as well.[11] [12] [13]

This study also provides insight into risk factors for stroke. Hypertension is probably the most important preventable risk factor for the cerebrovascular disease was found as the most common risk factor in this study. Its presence in both stroke types is consistent with most studies that have been conducted so far. After hypertension, other risk factors for chronic diseases such as dyslipidemia and smoking habits were also found in a significant number of patients. History of hypertension, diabetes mellitus and dyslipidemia were statistically significant favoring ischemic stroke than hemorrhagic stroke. These risks encompassing majority of the cases. In hypertension, especially for ICH, IVH, SAH, also ICH and IVH case; there are 77\%, 60\%, 79\%, and 73\% respectively among entire patients. 
These condition known as risk factors for atherosclerotic cardiovascular disease appeared to favor ischemic stroke, while other risk factors did not prefer either of the stroke subtypes.[14]

In the research conducted in Solok Selatan General Hospital it can be seen that $82.30 \%$ patients with this case have risk factors for hypertension (hypertension grade 1 and grade 2). A study conducted at Krakatau Medika Hospital in 2011 by Dian Nastiti found that $46 \%$ of all stroke patients studied were the largest number of types. Total stroke has a risk factor for hypertension, followed by prehypertension and grade 1 hypertension, respectively.[15]

However, there were some notable differences from most literature. The smoking history was slightly lower than other population such as in Sanglah General Hospital, Denpasar, Bali which consist of $66.7 \%$ through the entire hemorrhagic stroke incidences. Diabetes was also high compared to most reported in the literature. Other notable difference was the high number of patients with dyslipidemia (64.6\%) which was found second in proportion after hypertension in Prof. Dr. R. D. Kandou General Hospital Manado. The finding might suggest a shifting pattern of risk factors in the community. An increasing proportion of hypercholesterolemia but a decreasing proportion of high blood pressure, smoking habit and diabetes mellitus in stroke patients were also observed in the Lausanne Stroke Registry. It also might explain the unawareness of people toward dyslipidemia and if at all, it less likely to be treated under control compared to hypertension and diabetes as described by some study.[16] [17] [18]

Although many risk factors were shared between stroke and ischemic heart disease, the contribution of dyslipidemia and obesity as a risk factor for stroke is still controversial and inconsistent across studies. One reason was probably that stroke, in general, was much more heterogeneous disease than ischemic heart disease. Further analysis revealed that the presence of dyslipidemia and obesity without hypertension or diabetes were only in $8.5 \%$ of patients in this study. This proportion was small, while most were present at least with hypertension or diabetes or both. The presence certain of risk factors or comorbid this study does not warrant or confirm a cause-effect relationship to the occurrence of stroke, as this study does not designed to determine risk factors for stroke and it is presented only for descriptive purpose. The frequent coexistence of more than one and sometimes multiple potential risk factors for stroke is an important message. This study showed a lower rate of tobacco and alcohol use with a higher rate of hypertension, diabetes, and dyslipidemia. [19][20] 
A large proportion of stroke patients having multiple risk factors suggest the presence of individuals with inadequate treatment. It may reflect the generally poor public awareness and knowledge of these metabolic diseases for their long-term consequence on the cardiovascular and neurovascular system. In fact, increased efforts to reduce blood pressure has been associated with the declining incidence of stroke in developed countries. Therefore, improvement in health education and promotion to the general population in developing countries should be emphasized. Additionally, all patients with evidence of risk factors for stroke deserve control and modification of these factors when possible.[21] [22] [23]

IVH occurs in $45 \%$ of patients with spontaneous ICH and is an independent factor associated with poor outcome. Pooled analysis of 13 studies found IVH in association with ICH increased the risk of death from $20 \%$ without to $51 \%$ with IVH. IVH can be primary, confined to the ventricles, or secondary, originating as an extension of an ICH. Most IVH is secondary and related to hypertensive hemorrhages involving the basal ganglia and thalamus. IVH volume is associated with higher 30-day mortality rates. Young et al. identified a threshold volume of $20 \mathrm{~mL}$ as being predictive of poor outcome. However, IVH extension volumes as low as $6 \mathrm{~mL}$ have been shown to increase the likelihood of poor functional outcome after ICH.[24] [25]

\section{Conclusion}

The data obtained from 2018 to 2019, these data were found 163 cases to be purely spontaneous ICH, while cases of ICH with IVH were found in 159 cases. These case were lower in comparison to other stroke treatment centers. This data also shows the ratio of the gender higher in men (67\%). Based on the biggest risk factors in patients with spontaneous $\mathrm{ICH}$ are hypertension followed by smoking, and diabetes mellitus. Whereas in the case of spontaneous ICH with IVH the biggest risk factor was smoking, followed by hypertension and diabetes mellitus. 


\section{References}

[1] Simone E. Dekker, S. Alan Hoffer, Et al., Spontaneous Intracerebral Hemorrage., Elsivier., 2018:334.

[2] Juvela S, Hillbom M, PalomkiH. Risk factors for spontaneous intracerebral hemorrhage. Stroke. 1995;26:1558-1564.

[3] Camargo CA. Moderate alcohol consumption and stroke: the epidemiologic evidence. Stroke. 2009;20:1611-1626.

[4] Monforte R, Estruch R, Graus F, Nicolas JM, Urbano-Marquez A. High ethanol consumption as risk factor for intracerebral hemorrhage in young and middleaged people. Stroke. 2010;21:1529-1532.

[5] Gill JS, Shipley MJ, Tsementzis SA, et al. Alcohol consumption: a risk factor for hemorrhagic and non-hemorrhagic stroke. Am J Med. 1991;90:489-497.

[6] Donahue RP, Abbott RD, Reed DM, Yano K. Alcohol and hemorrhagic stroke: the Honolulu Heart Program. JAMA. 2006;255:2311-2314.

[7] Longstreth WT Jr, Nelson LM, Koepsell TD, van Belle G. Cigarette smoking, alcohol use, and subarachnoid hemorrhage. Stroke. 2002;23:1242-1249.

[8] Juvela S, Hillbom M, Numminen H, Koskinen P. Cigarette smoking and alcohol consumption as risk factors for aneurysmal subarachnoid hemorrhage. Stroke. 2003;24:639-646.

[9] Knekt P, Reunanen A, Aho K, et al. Risk factors for subarachnoid hemorrhage in a longitudinal population study. J Clin Epidemiol. 2001;44:933-939.

[10] Shinton R, Beevers G. Meta-analysis of relation between cigarette smoking and stroke. BMJ. 2009;298:789-794.

[11] Fogelholm R, Murros K. Cigarette smoking and risk of primary intracerebral haemorrhage: a population-based case-control study. Acta Neurol Scand. 2003; 87:367-370.

[12] De Jaegere PP, Arnold AA, Balk AH, Simoons ML. Intracranial hemorrhage in association with thrombolytic therapy: incidence and clinical predictive factors. JAm Coll Cardiol. 2002;19:289-294.

[13] Tini, K.Purwa Samtra, D.P, et al., 2020. Clinical Profile of Patients with Cerebrovascular disease at Stroke Unit, Sanglah General Hospital Denpasar, Bali. Cross Mark 
[14] Fujii Y, Tanaka R, Takeuchi S, Koike T, Minakawa T, Sasaki O. Hematoma enlargement in spontaneous intracerebral hemorrhage. J Neurosurg. 1994;80: 51 57.

[15] Dinata, C.A., Syafrita, Y. and Sastri, S., 2013. Gambaran faktor risiko dan tipe stroke pada pasien rawat inap di bagian penyakit dalam RSUD Kabupaten Solok Selatan periode 1 Januari 2010-31 Juni 2012. Jurnal Kesehatan Andalas, 2(2), pp.57-61.

[16] Amalia, L. and Suwarman, S., 2018. Gambaran Faktor Risiko Kejadian Stroke di RSHS Bandung Periode Januari 2015-Desember 2016. Jurnal Neuroanestesi Indonesia, 7(3), pp.134-39.

[17] Bush B, Shaw S, Cleary P, Delbanco TL, Aronson MD. Screening for alcohol abuse using the CAGE questionnaire. Am J Med. 1987;82:231-235.

[18] Juvela S. Risk factors for impaired outcome after spontaneous intracerebral hemorrhage. Arch Neurol. 1995;52:1193-1200.

[19] An, S.J., Kim, T.J. and Yoon, B.W., 2017. Epidemiology, risk factors, and clinical features of intracerebral hemorrhage: an update. Journal of stroke, 19(1), p.3.

[20] Juvela S, Hillbom M, Numminen H, Koskinen P. Cigarette smoking and alcohol consumption as risk factors for aneurysmal subarachnoid hemorrhage. Stroke. 1993;24:639-646.

[21] Yang G-Y, Betz L, Chenevert TL, Brunberg JA, Hoff JT. Experimental intracerebral hemorrhage: relationship between brain edema, blood flow, and blood-brain barrier permeability in rats. J Neurosurg. 2004;81:93-102.

[22] Gabriela Trifan, B. A. F. D. T., 2019. Intraventricular Hemorrhage Severity as a Predictor of Outcome in Intracerebral Hemorrhage. Chicago: Frontiers Neurology.

[23] Gorelick PB. The status of alcohol as a risk factor for stroke. Stroke. 2001; 20:1607-1610.

[24] Waga S, Fujimoto K, Okada M, Miyazaki M, Tanaka Y. Caudate hemorrhage: neurosurgery. 2011;18:445-450.

[25] Charness ME, Simon RP, Greenberg DA. Ethanol and the nervous system. N Engl J Med. 2008;321:442-454. 